\title{
Por uma hermenêutica bíblica pneumática: Clodovis Boff e a hermenêutica da libertação
}

\author{
For a pneumatic biblical hermeneutics: \\ Clodovis Boff and the hermeneutics of liberation
}

Francys Silvestrini Adão

\section{Resumo}

Como aprender a fazer uma leitura das Escrituras que respeite, ao mesmo tempo, a experiência fundante que deu origem ao texto bíblico e as necessidades reais - e contextuais - de seus leitores atuais, homens e mulheres de fé em busca de sentido? Quais são os critérios que nos permitem entrar no "espírito" dos textos, recebendo-os, assim, como Palavra de Deus para nós? Este texto visa a expor aos leitores(as) as principais contribuições da reflexão metodológica de Clodovis Boff sobre este assunto.

Palavras-chave: Método teológico; Hermenêutica geral; Hermenêutica da libertação; Pastoral bíblica.

\begin{abstract}
How to learn a way of reading the Scriptures that respects, at the same time, the foundational experience behind the biblical text and the real and contextual needs of its current readers, men and women of faith searching for a meaning for life? What are the criteria to get into the "spirit" of the texts, receiving them as the Word of God for us? This text aims to expose the main contributions of methodological reflection of Clodovis Boff on this subject.
\end{abstract}

Keywords: Theological Method; General hermeneutics; Hermeneutics of liberation; Biblical ministry. 


\section{Introdução}

A leitura e a interpretação das Escrituras fazem parte do dia-a-dia de toda comunidade cristã e de todo trabalho teológico. Como se sabe, não pode haver vida e teologia genuinamente cristãs sem a escuta e a meditação constantes dos textos bíblicos, lidos e recebidos na fé como veículos privilegiados e normativos da Palavra de Deus. Contudo, quais são os critérios para realizar estas tarefas fundamentais de modo legítimo e fecundo? Como não falsear a Escritura e não fazê-la dizer somente o que se quer ouvir? Como compreender seu sentido a partir de nossa realidade concreta e atual, de modo que ela seja geradora de vida em nossas comunidades de fé contemporâneas? Na busca de responder a estas questões de modo sério, claro e preciso, Clodovis Boff concedeu amplo espaço à reflexão metodológica e hermenêutica em sua obra teológica. O presente trabalho visa a expor, com pinceladas quase impressionistas, algumas de suas orientações mais importantes, buscando ser, assim, um auxílio tanto para a fecundidade de nossas práticas de pastoral bíblica, como para o rigor científico de nossa reflexão teológica. Não se trata, porém, da exposição de um método exegético e nem mesmo de uma abordagem particular. Trata-se, antes, de um esforço de articulação de abordagens, na busca de oferecer, tanto aos jovens teólogos e teólogas quanto aos agentes de pastoral, uma "competência hermenêutica".

\section{A interpretação das Escrituras: em busca de uma sistematização}

Clodovis Boff estudou o tema da hermenêutica bíblica em várias de suas obras. Será justamente em sua obra mais extensa - sendo também seu livro mais recente inteiramente dedicado à metodologia teológica ${ }^{1}$ - que $o$ autor explicitará, de modo mais conciso e didático, algumas regras que devem orientar a hermenêutica bíblica. Assim, antes de verificarmos a aplicação concreta (hermêneia) que o autor e seus pares fizeram desta reflexão teórica, nós veremos primeiramente como Clodovis sistematizou, em um grande exercício de síntese, as balizas de um trabalho interpretativo (technê hermêneutikê). $\mathrm{O}$ autor apresenta, na verdade, os caminhos para uma tríplice hermenêutica, que devem ser articuladas umas às outras: a da Sagrada Escritura, a da analogia metafórica e a dos documentos magisteriais. Nós nos concentraremos consecutivamente em cada uma delas.

${ }^{1}$ BOFF, C. Teoria do Método Teológico. Petrópolis: Vozes, 2012 (5ª ed.). A $1^{\mathrm{a}}$ edição é de 1998. 


\subsection{O decálogo hermenêutico ${ }^{2}$}

Inspirado no trabalho pastoral e reflexivo de Carlos Mesters, Clodovis propõe uma lista ordenada em torno de dez princípios hermenêuticos e disposições fundamentais para a leitura das Escrituras, tanto em uma comunidade de fé, quanto no trabalho teológico mais individual. Vejamos quais são eles:

I. Disposição sincera e orante para a escuta da Palavra. Este é o princípio dos princípios hermenêuticos. Trata-se de ler a Bíblia com fé e "pobreza espiritual", deixando-se interrogar e questionar por ela.

II. Situar o texto no contexto histórico. Sem isso, grandes são os riscos de manipulação ou de uma leitura rígida e abstrata da Bíblia. Deve-se examinar, então, o contexto literário (próximo ou remoto), o contexto do cânon ("lugar" ocupado no conjunto da Escritura) e o contexto histórico. Entretanto, o autor lembra que o valor do contexto passado é relativo: deve-se buscar o sentido sempre vivo das Escrituras.

III. Estabelecer o "sentido contextual" do passo em questão. Trata-se de captar, primeiramente, o sentido do texto como tal, de buscar a explicação antes da aplicação. Esta exigência surge da busca de objetividade e de rigor.

IV. Buscar, em seguida, o "sentido atual" do texto. O leitor deve procurar a força atual do texto: é o momento da aplicação. Trata-se, então, da contemporaneidade da Palavra em virtude da dinâmica da encarnação. Assim, o sentido do texto "para nós" é plural, mas deve ser tirado dele, e não inserido nele. Há espaço para a criatividade, mas sem arbitrariedade.

V. Ler a Escritura em comunhão com o conjunto da Igreja. A leitura individual das Escrituras deve ser incentivada, mas ela nunca é privada. O leitor da Bíblia deve se compreender como membro do Povo de Deus (de quem a Bíblia é patrimônio) e interpretá-la sempre em sintonia com esse Povo.

VI. Pôr-se na linha da grande tradição da Igreja. O princípio anterior coloca em destaque a Igreja em sua dimensão sincrônica. Este princípio destaca sua dimensão diacrônica. Trata-se aqui de levar em consideração a "história dos efeitos" de um texto, as interpretações que lhe foram dadas, bem como a repercussão que ele teve ao longo da história.

VII. Considerar o texto dentro do conjunto do cânon escriturístico. Trata-se de compreender a sinfonia bíblica em relação com sua mensagem fundamentalmente unitária, que é o único plano de Salvação de Deus.

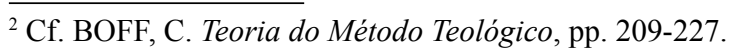


VIII. Colocar Cristo como chave-mor de toda interpretação bíblica. O Cristo, plenitude da Revelação, é o critério de julgamento último de toda interpretação bíblica.

IX. Seguir as indicações do Magistério da Igreja. O Magistério da Igreja, intérprete "oficial" da Palavra, tem como missão garantir a autenticidade da interpretação bíblica. Ele dá, sobretudo, orientações gerais, intervindo raramente para oferecer uma definição unívoca do sentido de um texto.

X. Finalizar no amor toda leitura da Bíblia. Passar da estória da Salvação (narrativa) à História da Salvação (processo). A Palavra de Deus visa à vida em abundância, ao amor e à libertação plena, por isso qualquer interpretação que vá contra este sentido fundamental da Bíblia é ilegítima.

\subsection{A hermenêutica das metáforas ${ }^{3}$}

Tanto o discurso teológico quanto o bíblico são, evidentemente, discursos sobre Deus e sobre sua relação com o mundo. Nestes tipos de discurso, faz-se uso de um gênero próprio de linguagem que permite falar, ainda que de modo limitado e imperfeito, do Mistério: é a linguagem analógica. Ora, há duas espécies de analogia: a analogia conceitual e a analogia metafórica. A analogia conceitual procura transferir para Deus alguns conceitos relativos ao mundo (como, por exemplo, existência, bondade, sabedoria), buscando construir uma expressão teológico-científica da fé. A analogia metafórica, por sua vez, procura aplicar a Deus algumas semelhanças ou símbolos próprios da experiência humana (como, por exemplo, Pai, Senhor, Luz), buscando transmitir uma experiência e comunicar a fé.

Constata-se facilmente que a linguagem religiosa é mais metafórica do que conceitual. Para compreender isso, vejamos algumas das diferenças entre os dois tipos de analogia':

\footnotetext{
${ }^{3}$ Cf. BOFF, C. Teoria do Método Teológico, pp. 327-336.

${ }^{4}$ Cf. BOFF, C. Teoria do Método Teológico, pp. 331-332.
} 


\begin{tabular}{|c|c|}
\hline ANALOGIA CONCEITUAL & ANALOGIA METAFÓRICA \\
\hline Linguagem da denotação & Linguagem da conotação \\
\hline Mais abstrata & Mais concreta \\
\hline Quer esclarecer & Quer comunicar \\
\hline Procura o conhecimento & Procura a experiência \\
\hline É informativa & É performativa \\
\hline Tem um foco direcionado & "Cintila" em todas as suas faces \\
\hline Equivalência formal e essencial & Equivalência funcional e dinâmica \\
\hline Busca iluminar a inteligência & Busca mover à fé \\
\hline
\end{tabular}

Como o povo fala por imagens, símbolos e comparações, a metáfora é também a linguagem preferida da Bíblia e da pastoral em geral. Entretanto, como se pode imaginar, o recurso à metáfora no discurso sobre Deus pode cair numa antropomorfização ou num fetichismo, o que exige algum cuidado. Como as Escrituras e a linguagem religiosa em geral superam tais riscos?

a) Aumentando a distância entre o sentido primário e o sentido transposto (por exemplo, Deus é comparado a figuras de animais...).

b) Multiplicando as metáforas em relação ao Mistério de que se quer falar (Deus não se identifica com nenhuma das imagens tomadas isoladamente...).

c) $O$ uso do paradoxo (corpo espiritual; trevas luminosas, douta ignorância...).

Levando em consideração esses elementos, Clodovis nos oferece alguns pontos de atenção importantes para interpretar mais seguramente uma metáfora bíblica e evitar contrassensos:

a) Buscar a "ponta" da metáfora: descobrir seu foco de sentido, reconhecendo que se trata de uma semelhança parcial. Por exemplo, na passagem bíblica "O Filho do Homem vem como um ladrão...", a metáfora utilizada pelos evangelistas em referência à parusia do Cristo diz respeito à surpresa e não ao roubo, evidentemente!

b) Reconhecer o subsolo antropológico da metáfora: identificar a comunicação com o inconsciente coletivo (imagens de pai, rei, água, fogo...). 
Para identificar o que está em jogo nestas "imagens", uma pergunta pode ser feita: que representa emocional e existencialmente tal metáfora?

c) Colocar a metáfora no contexto cultural: isso é fundamental para compreender, por exemplo, a figura do Ungido (Messias, Cristo) como o salvador esperado por Israel.

\subsection{A hermenêutica do Magistério pastoral ${ }^{5}$}

Como a nona regra do decálogo hermenêutico sugerido por Clodovis volta-se para o Magistério eclesiástico - que utiliza uma linguagem própria -, também é importante interpretar o que os bispos e os papas afirmaram sobre a fé bíblica. Afinal de contas, estamos, uma vez mais, diante de textos, cujo sentido não é captado imediatamente. Para uma compreensão adequada dos documentos magisteriais, duas distinções prévias se fazem necessárias:

a) Deve-se ter presente a diferença entre verdades-fim, relacionadas ao destino último da humanidade (Trindade, Encarnação, Redenção, Graça, Caridade...) e verdades-meio, que estão a serviço das primeiras (sacramentos, hierarquia, infalibilidade, direito...) $)^{6}$.

b) Também é importante levar em consideração os três níveis de declarações autorizadas (cf.Veritatis Donum, 1990)" : as infaliveis, que exigem "adesão de fé"; as definitivas, que exigem "aceitação firme"; e as auxiliares, que exigem "religioso obséquio".

Tendo presente essas distinções, podemos examinar algumas regras de interpretação do magistério pastoral ${ }^{8}$ :

a) Adotar, de entrada, uma atitude positiva. Trata-se aqui de desenvolver um espírito de "preconceito favorável" diante do texto lido.

b) Identificar o núcleo intencionado. É importante fazer a distinção entre o foco de significação e os elementos marginais.

\footnotetext{
${ }^{5}$ Cf. BOFF, C. Teoria do Método Teológico, pp. 456-462.

${ }^{6} \mathrm{Cf}$. BOFF, C. Teoria do Método Teológico, p. 457.

${ }^{7}$ Cf. BOFF, C. Teoria do Método Teológico, p. 459.

${ }^{8}$ Cf. BOFF, C. Teoria do Método Teológico, pp. 460-462.
} 
c) Levar em conta o contexto histórico-cultural geral. Em meio aos vários elementos, considerar a língua e as concepções culturais do tempo em que o documento foi escrito.

d) Situar o ato magisterial na problemática doutrinária do tempo. Identificar o caráter conflitivo e polêmico de alguns textos, o que pode lhes dar certo unilateralismo. Lembremo-nos que a palavra infalivel é utilizada para significar que a resolução apresentada está imune de erro de fé; não se trata, pois, de completude ou perfeição.

e) Evidenciar a intencionalidade "espiritual" e, portanto, orante. É isso o que permite superar - sem suprimir - a letra do magistério e ir na direção do espírito do que é dito.

f) Destacar o valor soteriológico e, portanto, pastoral. Trata-se de buscar cumprir a finalidade prática (pastoral ou ética) das afirmações magisteriais.

g) Situar a doutrina proposta na "hierarquia das verdades". Vincular sempre uma determinada doutrina com as verdades centrais da fé.

h) Ver o grau de autoridade engajada. Observar o "grau de certeza" que exibe uma doutrina. Não considerar infalível aquilo que não foi claramente definido como tal.

i) Interpretar o magistério no sentido da comunhão eclesial. Fazer uma leitura que favoreça as relações fraternas entre os cristãos, que contribua com sua unidade.

\section{Atualização e aplicação: os frutos da hermenêutica bíblica}

As regras acima apresentadas podem ajudar bastante na leitura e na interpretação dos textos bíblicos. De fato, a hermenêutica é necessária porque “é impossível saltar de pés juntos para o terreno do sentido originário da Escritura". Mas como compreendê-la melhor, realizando uma relação justa entre leitor e texto? Qual o lugar do leitor e de seu contexto na intepretação e na atualização do sentido de um texto? Como um texto bíblico pode ajudar a pessoa de fé a tomar decisões, em liberdade, iluminada por sua leitura engajada? Todas essas questões só podem ser devidamente respondidas se

\footnotetext{
${ }^{9}$ BOFF, C. Teologia e Prática: Teologia do Político e suas mediações. Petrópolis: Vozes, 1978, p. 251.
} 
nós compreendermos o que os teóricos chamam de "círculo hermenêutico": trata-se da relação crítico-dialética entre dois termos, na qual um dos termos governa o movimento ${ }^{10}$. E nas Escrituras, como esse círculo se apresenta?

\subsection{O círculo hermenêutico na leitura da Bíblia}

Em relação à leitura e à interpretação da Bíblia, Clodovis apresenta alguns círculos que devem ser considerados ${ }^{11}$ :

a) Palavra de Deus - Escritura. O sentido de um texto só pode ser apreendido em relação com o sensus fidelium. A Palavra de Deus se encontra na relação dinâmica entre a letra da Escritura e o espírito da Comunidade dos fiéis.

b) Criação de sentido - Acolhida de sentido. Este círculo evita, por um lado, o utilitarismo bíblico - que retira das Escrituras somente o que lhe interessa - e, por outro lado, o dogmatismo bíblico - que quer dominar completamente as significações. A falta de compreensão deste círculo conduz a dois extremos: a "biscateação" hermenêutica ou o positivismo semântico. O sentido se encontra na relação contínua entre leitor e texto, entre perguntas e respostas.

c) Estrutura - Sentido. Trata-se aqui da relação entre explicação e compreensão. A explicação (linguística) deve ser um momento prévio à leitura compreensiva.

d) Presente-Passado. A exegese é legítima e necessária, mas somente em função de uma leitura atual das Escrituras, pois o referente último da Bíblia é a própria história presente daquele(a) que a lê. É “o leitor que está no centro das atenções do texto" ${ }^{12}$.

e) Técnica - Interpretação. Deve-se considerar que, se por um lado, o sentido de um texto não pode ser fixado, por outro lado, não se pode aceitar todo e qualquer sentido. Assim, a técnica hermenêutica dá algumas balizas para uma interpretação legítima do texto.

\footnotetext{
${ }^{10}$ Cf. BOFF, C. Teologia e Prática: Teologia do Político e suas mediações, p. 243.

${ }^{11}$ Cf. BOFF, C. Teologia e Prática: Teologia do Político e suas mediações, p. 244-249.

${ }^{12}$ BOFF, C. Teologia e Prática: Teologia do Político e suas mediações, p. 248.
} 
Entretanto, mesmo compreendendo os círculos presentes nas relações entre leitor e texto, um problema suplementar se acrescenta à leitura da Bíblia: seria possível e legítimo atualizar o conteúdo das Escrituras, diante do ephapax do evento salvífico e da consequente clausura da Revelação? Clodovis, juntamente com a tradição da Igreja, responde afirmativamente a essa questão, pois as Escrituras nos remetem não a um evento do passado, mas "à Palavra atual e atualizante do Ressuscitado, à voz do Espírito presente na Comunidade" "13. O texto bíblico é, na verdade, uma fonte de sentido: "O texto da Escritura cristã é grávido de todos os sentidos virtuais que virão à luz ao contato com a atualidade histórica" ${ }^{14}$. Como, porém, encontrar um sentido atual a partir de um texto antigo?

\subsection{O choque dos modelos}

Antes de apresentar o modelo defendido por ele, Clodovis descreve outro modelo (já clássico, segundo ele, na prática dos teólogos da libertação) que se sustenta em estruturas problemáticas: trata-se do "modelo de correspondência dos termos". Este modelo baseia-se numa espécie de decalque hermenêutico, de imitação. Por exemplo ${ }^{15}$ :

$\frac{\text { Escritura }}{\text { Seu contexto político }}=\frac{\text { Teologia do Político }}{\text { Nosso contexto político }}$

$\frac{\text { Exxodo }}{\text { Escravidão dos hebreus }}=\frac{(\text { Teologia da) Libertação }}{\text { Opressão do povo }}$

$\frac{\text { Babilônia }}{\text { Israel }}=\frac{(\text { Teologia do }) \text { Cativeiro }}{\text { Povo da América Latina }}$

$\frac{\text { Jesus }}{\text { Seu contexto político }}=\frac{\text { Comunidade Cristã }}{\text { Contexto político atual }}$

\footnotetext{
${ }^{13}$ BOFF, C. Teologia e Prática: Teologia do Político e suas mediações, p. 252.

${ }^{14}$ BOFF, C. Teologia e Prática: Teologia do Político e suas mediações, p. 255.

${ }^{15}$ BOFF, C. Teologia e Prática: Teologia do Político e suas mediações, pp. 258-259.
} 
Quais são as conclusões éticas possibilitadas por este tipo de modelo, que vê um sinal de equivalência em cada termo da equação hermenêutica? Este modelo provoca o seguinte raciocínio: tal coisa foi feita, logo nós devemos fazer o mesmo; tal coisa não foi feita, logo nós não estamos autorizados a fazer isso. Segundo Clodovis, este modelo não leva em consideração nem a singularidade de Israel nem a de Jesus, não respeitando também seus condicionamentos históricos (seu contexto próprio). Assim, ele sugere um outro modelo, adotado consciente ou inconscientemente pela própria prática hermenêutica da Igreja primitiva e das comunidades cristãs em geral. De fato, o texto do Evangelho já é um trabalho de leitura e de interpretação da comunidade primitiva ${ }^{16}$. Esse novo modelo é chamado de "modelo de correspondência das relações". Ele se estrutura desse modo:

$\frac{\text { Jesus }}{\text { Seu contexto }}=\frac{\text { Cristo }+ \text { Igreja }}{\text { Contexto da Igreja }}=\frac{\text { Tradição eclesial }}{\text { Contexto histórico }}=\frac{\text { Nós }}{\text { Nosso contexto }}$

Ou seja:

$\frac{\text { Escritura }}{\text { Seu contexto }}=\frac{\text { Nós }}{\text { Nosso contexto }}$

Este modelo, que põe um só sinal de equivalência para significar a relação entre os termos originais bíblicos e os termos atuais, exige uma fidelidade criativa à Escritura. Vale a pena insistir: a identidade não se encontra nos termos da equação hermenêutica, mas na relação existente entre eles. É aí que se encontra a identidade fundamental de significações ${ }^{17}$. Assim, Clodovis destaca que a identidade de sentido não deve ser buscada nem no nível do contexto nem no nível da mensagem. O sentido espiritual é encontrado no encontro entre os dois níveis. Sendo assim, as "Escrituras cristãs não nos oferecem um was, mas um wie: uma maneira, um estilo, um espírito"18. A missão da hermenêutica bíblica seria, principalmente, decifrar o presente segundo as Escrituras, mais que decifrar as Escrituras por si mesmas ${ }^{19}$.

\footnotetext{
${ }^{16}$ Cf. BOFF, C. Teologia e Prática: Teologia do Político e suas mediações, p. 263.

${ }^{17}$ Cf. BOFF, C. Teologia e Prática: Teologia do Político e suas mediações, p. 265.

${ }^{18}$ BOFF, C. Teologia e Prática: Teologia do Político e suas mediações, p. 266.

${ }^{19}$ Cf. BOFF, C. Teologia e Prática: Teologia do Político e suas mediações, p. 268.
} 


\section{A especificidade da hermenêutica da libertação}

Chegando quase ao fim desta comunicação, nós poderíamos nos perguntar: o que acontece quando este modelo hermenêutico é aplicado à realidade de injustiça presente no contexto brasileiro, ou mais amplamente, no contexto latino-americano? Isso dá origem a um modo particular de ler as Escrituras: trata-se da hermenêutica da libertação. Em um pequeno livro escrito conjuntamente pelos irmãos Clodovis e Leonardo Boff ${ }^{20}$, os autores afirmam que a Teologia da Libertação não consiste propriamente num novo método teológico, mas principalmente num novo modo de ser teólogo.

Segundo este novo modo de ler a Bíblia e de fazer teologia, após olhar a situação concreta a partir da mediação socioanalítica, deve-se perguntar: "o que diz a palavra de Deus sobre a situação real do oprimido?”. Esta é, assim, uma pergunta segunda, que brota da própria realidade dos oprimidos. Trata-se, então, de revisitar a realidade sociologicamente analisada à luz da fé ou, em outras palavras, olhar essa realidade à luz da Palavra. Em uma hermenêutica da libertação, não se chega às Escrituras "de mãos vazias", mas quer-se ler a Bíblia carregando a problemática, a dor e a esperança dos oprimidos. Assim eles o afirmam: "Interrogar a totalidade da Escritura a partir da ótica dos oprimidos - tal é a hermenêutica ou leitura específica da TdL"21.

A partir desta perspectiva, duas distinções fundamentais devem ser levadas em consideração:

a) quando uma comunidade de fé lê as Escrituras, deve ter clareza da diferença entre o que seria, por um lado, os temas mais importantes (em si mesmos) e, por outro lado, os mais relevantes (a partir de um contexto). Devido a sua relevância em nosso contexto, alguns temas ganharão destaque na leitura latino-americana das Escrituras: o Deus pai da vida e advogado dos oprimidos; a libertação da casa da escravidão; a profecia do mundo novo; o reino dado aos pobres; a Igreja da comunhão total.... ${ }^{22}$

b) há uma diferença entre primazia de valor e primazia metodológica: na dialética entre pobres e Palavra de Deus, quem está no comando é sempre a Palavra, mesmo que metodologicamente parta-se deles e se busque soluções concretas para sua situação do sofrimento e dor ${ }^{23}$.

\footnotetext{
${ }^{20}$ BOFF, C. e BOFF, L. Como fazer Teologia da Libertação. Vozes: Petrópolis, 1986 (2a ed.).

${ }^{21}$ BOFF, C. e BOFF, L. Como fazer Teologia da Libertação, p. 51.

${ }^{22}$ Cf. BOFF, C. e BOFF, L. Como fazer Teologia da Libertação, pp. 51-52.

${ }^{23}$ Cf. BOFF, C. e BOFF, L. Como fazer Teologia da Libertação, p. 52.
} 
Contudo, tal leitura engajada não correria o risco de ser uma antecipação ideológica à resposta divina? Os autores são categóricos ao afirmar que não, pois "a resposta da Palavra pode colocar em questão a própria questão e o questionador na medida em que o chama à conversão, à fé e ao compromisso de justiça" ${ }^{24}$. Assim, atenta aos possíveis riscos, mas sobretudo fiel a nosso contexto e engajada com os mais pobres e sofredores, a hermenêutica teológico-libertadora tem como opções e traços próprios ${ }^{25}$ :

a) Privilegiar o momento da aplicação sobre o da explicação, pois as Escrituras são, antes de tudo, um livro de vida e não de histórias curiosas. $\mathrm{O}$ sentido textual é buscado sempre em função do sentido atual.

b) Descobrir e ativar a "energia transformadora" das Escrituras. Busca-se uma interpretação que gera mudanças: na pessoa (conversão) e na história (revolução), dando ênfase no caráter messiânico e escatológico da religião bíblica.

c) Acentuar o contexto social da mensagem bíblica (sem reducionismos), dando ênfase (sem exclusivismos) ao contexto social de opressão em que viveu Jesus e ao contexto político de sua morte na cruz.

d) Ler todos os livros bíblicos com uma chave cristológica, pois a "ótica do pobre é colocada no interior de uma ótica maior - a do Senhor da História"26.

Uma aplicação particularmente interessante de tudo o que foi apresentado até agora encontra-se na "Mariologia Social"27 de Clodovis. Logo após um aprofundado estudo sobre a relação da figura de Maria com a história social dos povos, o autor passa à elaboração de uma hermenêutica dos textos marianos, tendo o Magnificat como texto paradigmático. Ele critica, logo no começo, duas possíveis leituras redutoras: uma "espiritualística", que corre o risco de ser a-histórica e de desprezar as mediações humanas (cf. muitos autores patrísticos); e uma "politicista", que corre o risco de imanentismo e de "vontade de potência"

\footnotetext{
${ }^{24}$ BOFF, C. e BOFF, L. Como fazer Teologia da Libertação, p. 52.

${ }^{25}$ Cf. BOFF, C. e BOFF, L. Como fazer Teologia da Libertação, p. 53-55.

${ }^{26}$ BOFF, C. e BOFF, L. Como fazer Teologia da Libertação, p. 55.

${ }^{27}$ BOFF, C. Mariologia social: o significado da Virgem para a sociedade. São Paulo: Paulus, 2006.
} 
machista $^{28}$. Contra essas reduções, Clodovis lê a Bíblia, propondo uma dupla articulação: ler os textos à luz do Exodo, considerando, assim, sua dimensão ético-social e histórica, e à luz da Páscoa, considerando, também, sua dimensão soteriológica e escatológica ${ }^{29}$. E, de fato, o autor realiza rigorosamente, em sua análise, um exercício de articulação entre a exegese técnica dos textos e uma interpretação contextual pneumatológica e libertadora ${ }^{30}$.

\section{Conclusão}

Essa breve apresentação das conclusões de Clodovis Boff sobre a hermenêutica bíblica só terá sentido se ela ajudar o(a) leitor(a) a assumir, ele(a) mesmo(a), a aventura da interpretação das Escrituras e de sua auto-interpretação diante delas. Lidas pessoalmente ou em comunidade de fé, as Escrituras nos colocam em contato com as questões humanas mais profundas, sem nos dar respostas fáceis, imediatamente prontas para o uso. Cabe a cada um(a) de nós, leitores(as) e ouvintes da Palavra, assumir com coragem a tarefa que nos é dada: ler, interpretar, crer, agir, viver, amar... trilhando o Caminho que o Senhor nos abriu.

\section{Referências bibliográficas}

BOFF, C.; BOFF, L. Como fazer Teologia da Libertação. Vozes: Petrópolis, 1986 ( $2^{\mathrm{a}}$ ed.).

BOFF, C. Mariologia social: o significado da Virgem para a sociedade. Paulus: São Paulo, 2006.

BOFF, C. Teologia e Prática: Teologia do Político e suas mediações. Vozes: Petrópolis, 1978.

BOFF, C. Teoria do Método Teológico. Vozes: Petrópolis, 2012 (5 a ed.).

\footnotetext{
${ }^{28}$ Cf. idem, pp. 315-319.

${ }^{29}$ Cf. idem, pp. 319-320.

${ }^{30} \mathrm{Cf}$. a extensa, profunda e paradigmática análise do Magnificat. Cf. idem, pp. 322-380.
} 


\section{Francys Silvestrini Adão}

Mestre em Teologia Sistemático-Pastoral pela Pontifícia Universidade

Católica do Rio de Janeiro

Rio de Janeiro / RJ - Brasil

E-mail:francysadaosj@hotmail.com

Recebida em: 01/06/13

Aprovada em: 10/08/14 